\title{
GRASP with ALNS for solving the location routing problem of infectious waste collection in the Northeast of Thailand
}

\author{
Siwaporn Suksee ${ }^{\mathrm{a}}$ and Sombat Sindhuchao ${ }^{\mathrm{a}^{*}}$
}

${ }^{a}$ Department of Industrial Engineering, Faculty of Engineering, Ubon Ratchathani University, Ubon Ratchathani 34190. Thailand

\begin{tabular}{l}
\hline C H R O N I C L E \\
\hline Article history: \\
Received September 132020 \\
Received in Revised Format \\
November 282020 \\
Accepted January 222021 \\
Available online \\
January, 22 2021 \\
\hline Keywords: \\
GRASP (Greedy Randomized \\
Adaptive Search Procedure) \\
ALNS (Adaptive Large \\
Neighborhood Search) \\
Location-Routing Problem(LRP) \\
Infectious Waste \\
Northeast of Thailand
\end{tabular}

\section{Introduction}

All regions of the world are currently experiencing an infectious disease problem every year with a continuously increasing trend; as a consequence, medical science must be continually developed for the prevention, resistance and treatment of various diseases, resulting in a growing demand for medical consumables and equipment such as hypodermic syringes, cotton and bandages, et al. The medical consumables and equipment used for medical treatments are the cause of medical waste known as infectious waste. Infectious waste is classified as hazardous waste, which must be taken into consideration in the sanitary process of its storage, collection, transportation and disposal, especially at infectious waste disposal sites, because it directly affects the environment and people. (Almeida et al., 2009). Many years ago, Thailand had periodic experiences with Emerging Infectious Diseases (EIDs) as a result of increasing quantities of medical waste. In 2018, Thailand had a total of 55,497.22 tons of infectious waste generated from public hospitals, private hospitals, private clinics, veterinary hospitals and laboratories, totaling 38,235 sites. Approximately 50\% of infectious waste is generated from hospitals operating under the Ministry of Public Health and about 24\% from private hospitals and clinics. The amount of infectious waste is expected to increase by approximately 5.5\% (Department of Pollution Control Thailand, 2018). In the Northeast region of Thailand, there are 325 hospitals operating under the Ministry of Public Health. The total amount of infectious waste is approximately 15,798 kilograms per day, which is the second highest percentage in the country, behind the central region. In 2011, Seubsiri explained that each hospital has a policy to eliminate infectious waste through incineration. Most hospitals have their own incinerators, but some incinerators in a damaged condition are not operated. In addition, the ineffective incineration of infectious waste * Corresponding author

E-mail: somsin@,rocketmail.com (S. Sindhuchao)

2021 Growing Science Ltd. doi: $10.5267 /$ j.ijiec.2021.2.001

\begin{abstract}
This research proposes a heuristic to solve the problem of the location selection of incinerators and the vehicle routing of infectious waste collection for hospitals in the Northeast of Thailand.
The developed heuristic is called the Greedy Randomized Adaptive Large Neighborhood Search Procedure (GRALNSP) and applies the principles of the Greedy Randomized Adaptive Search
Procedure (GRASP) and Adaptive Large Neighborhood Search (ALNS) in the local search. The results from GRALNSP are compared with those from the exact method processed by the A experiments showed that both methods provided no different results with the global optimal solution, but GRALNSP required less computational time. When the problems were larger-scale computational time while GRALNSP provided better results with much less computational time. In solving the case study with GRALNSP, the result shows that the suitable locations for opening infectious waste incinerators are the locations of Pathum Ratwongsa district, Amnat Charoen
province and Nam Phong district, Khonkaen province. An incinerator with a burning capacity of $600 \mathrm{kilogram} / \mathrm{hour}$ is used at both locations. The monthly total distances for infectious waste collection are $24,055.24$ and $38,401.88$ kilometers, respectively, and the lowest total cost is $6,268,970.40$ baht per month.
\end{abstract}

C 2021 by the authors; licensee Growing Science, Canada

\section{(20.5.}


with inefficient incinerators causes environmental impacts on neighboring communities and is often strenuously objected to by local residents (Theeraviriya et al., 2020) Most hospitals require an outsourced waste disposal company to manage waste instead of getting rid of the waste by itself, which is very costly. Small health care facilities and some hospitals send infectious waste to be disposed of together with networked government hospitals. In 2018, the Department of Pollution Control Thailand (2018) reported on the infectious waste situation in Thailand and found that only $89.91 \%$ of total infectious waste was managed properly. As for the remaining amount of infectious waste, it could not be examined. Improper handling and disposal of infectious waste is often carried out by open-air-garbage-disposal, which is not maintained in a sanitary condition, or by illegally dumping the infectious waste mixed with regular waste. The Thai government has established a policy to encourage the correct disposal of waste by assigning local governments in Thailand to supervise and manage the disposal and prescribing that the public health service facilities conduct proper infectious waste management. However, local governments in Thailand have policies and the ability to deal with only $2.3 \%$ of infectious waste (Maneein, 2013); therefore, the public health facilities are assigned to operate by themselves. This problem shows that planning for infectious waste disposal, especially the establishment of infectious waste disposal sites and the effective collection of infectious waste in the Northeast of Thailand, is necessary. Therefore, choosing a suitable area for the establishment of infectious waste disposal sites that can serve customers thoroughly (Almeida et al., 2009; Boyer et al., 2013; Rakas et al., 2004) and finding safe and fast transportation routes for infectious waste collection will reduce the impact on the environment, health and hygiene and society, as well as the cost of infectious waste disposal at the lowest possible level. Selecting a suitable location for incinerator establishment and the shortest distance of infectious waste collection routes are classified as Location Routing Problems (LRPs), where the location selection process and routing are carried out at the same time (Prodhon and Prins, 2014) with the lowest total cost. As a solution to the above problem, this paper focuses on the selection of incinerator locations and the routing of infectious waste collection from hospitals to waste disposal sites located in the Northeast districts of Thailand with the aim of obtaining the lowest total cost, including the cost of infectious waste incineration, transportation costs and penalty costs. When considering potential locations for infectious waste disposal, it is necessary to consider areas that are not against the law and result in the least impact on society and the environment. In addition, the routing of infectious waste collection must consider the shortest distance and the conditions required. This research therefore proposes the mathematical model and solves problems with the A Mathematical Programming Language (AMPL) program. However, due to the characteristics of the problem being complicated and the fat that the problem is NP-hard, AMPL may be unable to solve it; thus, the author proposes a heuristic method developed by applying the principles of the Greedy Randomized Adaptive Search Procedure (GRASP) and the Adaptive Large Neighborhood Search (ALNS) in the local search. The rest of the paper is organized as follows: Section 2 presents related literature, Section 3 presents the problem description and mathematical formulation, Section 4 presents the heuristics development, the results and discussion of the developed heuristics are provided in Section 5, and finally, Section 6 provides our conclusions.

\section{Literature review}

The incinerator site is a location that can pose potential hazards to the environment and sanitation; as it is classified as an undesirable facility, it should not be located in a crowded area and should have minimal impact on the environment and the economy. For an extensive discussion on undesirable facility locations, in 1989, Erkut and Neuman published a review of the location of undesirable facilities, with the aim of minimizing the adverse effects of the existing facilities on population centers. Although the service cost of an undesirable facility increases when the facility is located far from the population centers, the undesirability of the facility usually seems to be important. In 2006, Norese implemented the principle of multi-criteria analysis in their decision to choose a disposal site and incinerator site in Italy, considering the aspects of local traffic conditions and the inherent consequences on social equity and the natural and social environment when determining the disposal site. In addition, they determined the location of an incinerator site by considering the aspects of local development, environmental effects, self-sufficiency and social equity. Tuzkaya (2008) stated that the selection of undesirable facilities must consider both quantitative and qualitative criteria simultaneously and proposed the selection of undesirable facilities implementing the analytic network process (ANP) method. In 2013, Tang et al. gathered opinions on the selection of a landfill site. It was found that there were four main criteria, including 1) environmental and critical, 2) economic, 3) social and political and 4) infrastructure and foundation factors. In 2009, Almeida et al. adopted the concept of a multi-objectives model for determining an incinerator site and the amount of hazardous waste accommodated by the site area with five objectives: to reduce the investment cost for the establishment of an incinerator, to reduce the cost of operating the incinerator, to reduce the potential impact (measuring based on an average per person), to reduce the average of the greatest effects and to reduce the impact caused by the limitation of the waste amount waste incinerated not exceeding the incinerator's capacity. In addition, Geographic Information Systems (GIS) were used to help to determine a suitable location. Nevertheless, some of this research studied hazardous waste transportation with a large focus on hazardous waste transport risks and transportation costs. Zhao et al. (2012) concluded that most accidents arising from hazardous waste transportation were caused by three main factors: human factors, vehicles and facilities factors and hazardous waste packing and collection. In 2011, Kazantzi et al. presented a modeling framework to solve hazardous waste transportation networks with the objectives of reducing transportation costs and reducing the risks that may arise on roads, highways, urban roads and rural roads. Das and Bhattacharyya (2015) stated that the shortest route for the collection of municipal solid waste will affect the lowest costs of waste collection; therefore, they proposed a heuristic method for solving routing problems of municipal solid waste collection, resulting in a $30 \%$ reduction in the transport cost. Dotoli and Epicoco (2017) proposed techniques for routing hazardous waste collection and 
arranging a schedule of waste disposal collection for further destruction with the limitation of the shortest possible distance of waste collection but while maintaining the potential to collect the same amount of hazardous waste. In 2020, Yadav and Karmakar stated that the collection and transportation of municipal solid waste (MSW) contributes to the high total cost of municipal solid waste, which has to be taken into account in three main ways: 1) vehicle routing for municipal solid waste must be the shortest route, but can serve the most customers as well; 2) the facility location needs to be in a location in which municipal solid waste can be collected or destroyed at the lowest cost; and 3) flow allocation must be able to efficiently manage the flow of municipal solid waste in the urban center. According to the literature review on solving medical waste management, healthcare waste management or hazardous waste management, Chauhan and Singh (2016) found that the problem can be classified into two main issues: namely the determination of the optimum location for hazardous waste disposal and the determination of the optimal route strategies. Transportation costs will increase if the incineration site is located too far from the customers' locations. Therefore, hazardous waste management is necessary to consider both issues simultaneously, which is called the location routing problem (LRP). In 2007, Alumur and Kara proposed a mathematical model to solve the hazardous waste location routing problem by selecting locations for the storage and processing of hazardous waste, including the use of technology to select the locations for destroying hazardous waste and arranging suitable transportation routes with the objective of reducing the total cost and reducing the risk of hazardous waste transportation. Aboutahoun (2012) proposed a mathematical model for selecting the location of hazardous waste destruction or storage, as well as transportation routes, by mainly considering the cost of damages arising from an accident. A mathematical model is developed in conjunction with Floyd Warshall's algorithm to provide the shortest possible transport distances and the lowest risk of accidents. Boyer et al. (2013) proposed a bi-objective mixed integer programming model to solve the location routing problem of industrial waste with the objective of reducing total costs, including the transportation cost, operation cost, initial investment cost and cost savings from selling recycled waste and for the minimization of transportation risk. The risk of population exposure within a certain bandwidth along the route is used to measure transportation risk. Zhao and Verter (2015) solved the oil location routing problem by considering a suitable area to store oil, the amount of oil contained and oil transportation routes by changing the weight value in goal programming to reduce the potential environmental risks and also minimize the total costs. When applying this program to the case study, it was found that it can manage oil storage management, storage and loading volumes and the transportation route effectively. Wichapa and Khokhajaikiat (2017) proposed a solution to the infectious waste location routing problem by selecting an appropriate area for the establishment of infectious waste disposal facilities for community hospitals in upper Northeastern Thailand and implementing a hybrid fuzzy goal programming model, which hybridizes the fuzzy analytic hierarchy process and fuzzy goal programming. Later, in 2018, Wichapa and PorntepKhokhajaikiat (2018) determined the shortest possible distance for infectious waste collection by implementing the hybrid genetic algorithm, which hybridizes the genetic algorithm and local searches, including 2-Opt-move, Insertion-move and $\lambda$-interchange-move, resulting in the least total cost. Rabbani et al. (2018) proposed a solution to the industrial hazardous waste location-routing problem in the form of multi-objective evolutionary algorithms by adapting two metaheuristic algorithms, namely the Nondominated Sorting Genetic Algorithm (NSGA-II) and Multi-Objective Particle Swarm Optimization (MOPSO), by mainly considering hazardous waste types, production sites and transport routes to obtain the least total cost and transport risk costs.

The LRP has also been adopted to solve other problems, along with applying the principles, concepts and methods to obtain the best optimal solution (Koc, 2016). Schneider and Drexl (2017) explored the relevant research regarding the solution to determining the location and the transport route; it was found that the purpose of the solution still focused on achieving the lowest total cost. Most operations are processed by operating the distribution centers and allocating customers for service as well as arranging transportation routes. Meta-heuristics, namely Ant System (AS), the Genetic Algorithm, Memetic Algorithm (GA), Simulated Algorithm (SA), Greedy Randomized Adaptive Search Procedure (GRASP) and Tabu Search (TS), etc., have been applied for this purpose. The method of the Greedy Randomized Adaptive Search Procedure is considered to be an efficient and accurate method to find or determine potential locations. Most of the problems of vehicle transport routing are related to the multi-depot vehicle routing problems. Researchers' solutions have evolved from the original approach. Regarding the survey of Nagy and Salhi (2007), several methods of finding solutions have been applied to obtain the most effective results. Contardo et al. (2014) proposed a meta-heuristic method for solving LRP problems by applying GRASP in conjunction with the Column Generation Technique. Implementing a problem-solving process uses the principles of GRASP and local search to determine the group of locations and service customers, and then applies the Integer-Linear Program to arrange the transport route and improve the route with the Column Generation Technique. It was found that the results obtained from these methods were of a very high quality compared to other methods. Hamidi et al. (2014) propose the hybrid metaheuristic, GRASP and Tabu Search, for solving a complex multi-production four-layer capacitated location routing problem. The Results indicate that the proposed hybrid heuristic solves the problem effectively in terms of computational time and solution quality. Gao et al. (2016) proposed LRP solutions when selecting distribution centers and vehicle routing under everchanging environments, such as random traffic factors, vehicle density and cyclic traffic; this kind of arranged route contains a high vehicle density at certain times, and the method of the K-means algorithm in conjunction with KACO is used to solve the problem by considering three forms of ant migration attitudes, namely random immigrants, elitism-based immigrants and memory-based immigrants, to select the location of the distribution center and arrange transportation routes under a constantly changing environment. In addition, the results obtained from KACO are compared with other meta-heuristics methods, such as Simulated Annealing, Tabu search, the Genetic Algorithm, population ant colony (P-ACO) and the max-min ant system (MMAS). Li et al. (2015); Li et al. (2019) proposed the method of Adaptive Large Neighborhood Search (ANLS) to solve 
LRP and VRP problems; their results showed that algorithms with ANLS have very good potential in terms of response quality and processing time. In 2018, Sirirak and Pitakaso proposed a solution to LRP problems in the case of selecting a location for selling agricultural products and arranging agricultural farm tourism routes and buying agricultural products at various distribution centers in Chiang Rai, Thailand by adapting the Adaptive Large Neighborhood Search (ANLS) method to find results consisting of six destruction and five repair methods to obtain the most cost-effective travel routes. Theeraviriyaet et al. (2019) proposed a selection of Palm Oil Collection Center locations and arranged oil transportation routes with the aim of minimizing the total facility-opening cost, fixed cost of vehicle uses and fuel consumption cost. Theeraviriyaet et al. (2020) solve the problem of the location selection of electric vehicles with restricted distance in agriculture by implementing by ALNS principle for the lowest total cost. The researchers applied ANLS to solve the problem and compared the results with the exact method. The findings showed that the results obtained from the ANLS method were more effective than the results of the exact methods, both in terms of the results and the shorter response time.

Regarding the review of the abovementioned literature, it is found that the method of the disposal and transportation of hazardous materials needs to give priority to both the environmental and social impacts as well as the total costs that may arise from the management process. The infectious waste location-transportation problem of hospitals in Northeastern Thailand is also considered to be a location routing problem. In this paper, heuristic methods applying the principles of metaheuristics (namely the Greedy Randomized Adaptive Search Procedure and Adaptive Large Neighborhood Search) are proposed to solve the problems in order to obtain the best results and require the least response time. The contributions of this paper are as follows: (1) a mathematical model is developed from problems arising from real situations, and (2) the form of the solution implements the meta-heuristic method, namely the Greedy Randomized Adaptive Search Procedure and Adaptive Large Neighborhood Search, to find the best solution.

\section{Problem Description and Mathematical Formulation}

Northeastern Thailand consists of 21 provinces. There are 325 hospitals operating under the Ministry of Public Health, including community hospitals and provincial hospitals. Almost all hospitals have engaged agencies to dispose of infectious waste at a price of approximately 12-16 baht per kilogram, which makes up a high proportion of total hospital expenses. In order to reduce the total costs and implement proper sanitation disposal, as well as minimizing environmental and social impacts, it is imperative to select a suitable infectious waste disposal site and an infectious waste collection route which is able to provide comprehensive service to the hospitals with the possible shortest collection distance. According to Thai law, the area is divided into several parts for different uses and for the maximum benefit. In this research, the locations of the industrial area are considered as the possible locations of the incinerator waste disposal sites. Regarding the land use allocation according to the announcement of ministerial regulations which enforce the city plan for each province (purple area), each province may have many areas of this type, as shown in Fig. 1(a). There are a total of 21 potential locations for establishing incinerator sites in Northeastern Thailand, as shown in Fig. 1(b). Each location is able to choose to establish only one incinerator. In addition, each hospital can deliver infectious waste to only one determined incineration site. In this research, the size of an infectious waste incinerator from Sresanpila (2018), is referenced. It is a standardized and environmentally safe infectious waste incinerator and is commonly used by private companies. The incinerators considered consist of three types of incinerators: incinerators with a maximum burning rate of 100, 300 and 600 kilograms per hour. All types of incinerators can be operated continuously for several hours. To operate an incinerator each month, the incinerator must be preheated for 6 hours before continuously burning; then, the collected infectious waste can be burned completely. As regards the route of infectious waste collection of hospitals in Northeastern Thailand, each vehicle has a waste collection capacity of $10,000 \mathrm{~kg}$. The vehicle will collect all the infectious waste from each hospital and deliver it to the operated incinerator for burning.

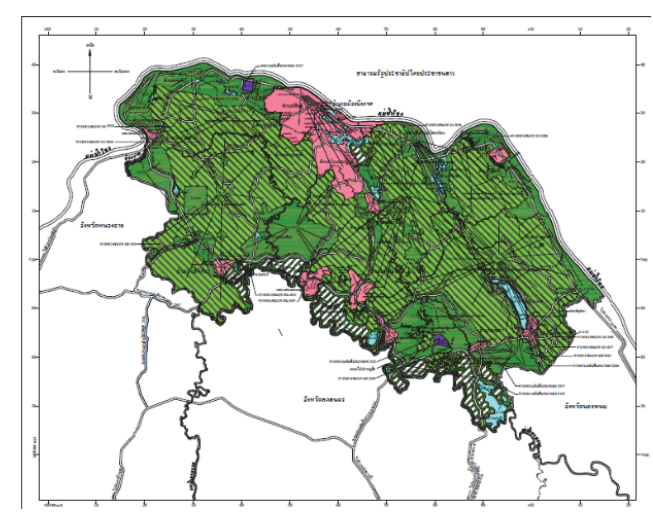

(a)

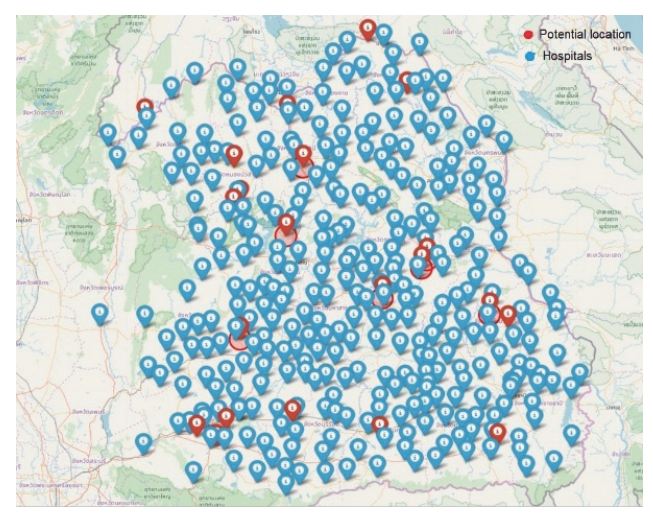

(b)

Fig. 1. (a) The example of the comprehensive city plan and (b) the potential locations and hospitals in the Northeast of Thailand. 
Hospitals using incinerator services have different frequencies of delivering infectious waste to be disposed of depending on each hospital's infectious waste disposal policy. On average, the community hospitals have a policy of eliminating infectious waste four times a month; provincial hospitals require the elimination of infectious waste eight times a month. Regarding the infectious waste collection process, each vehicle departs from the incinerator site and collects infectious waste from the nearest hospital first, then another hospital located near to the first hospital and others until a full load is reached; then, it travels back to the original location. As another requirement, the distance for collecting infectious waste along each route (round trip) for each vehicle must not exceed 750 kilometers. The total cost for the selection of potential locations and infectious waste collection routing includes fixed costs (employee wages and incinerator depreciation) and variable costs (fuel, utilities, incinerator maintenance) (Sresanpila, 2018) as presented in Table 1, as well as penalty costs, taking into account medical expenses, the average health insurance coverage per person, accounting for $259.60 \mathrm{baht} /$ person/month for the population in the radius of 5 kilometers (Energy Regulatory Commission, 2017) from the potential location of an infectious waste incinerator.

Table 1

Fixed cost and variable cost of infectious waste incinerators (Sresanpila, 2018)

\begin{tabular}{ccccc}
\hline \multirow{2}{*}{$\begin{array}{c}\text { Types of } \\
\text { Incinerator }\end{array}$} & \multicolumn{2}{c}{ Fixed cost } & \multicolumn{2}{c}{ Variable cost } \\
\cline { 2 - 5 } (baht/person/month) & $\begin{array}{c}\text { Staff salary } \\
\text { (baht/month) }\end{array}$ & $\begin{array}{c}\text { Fuel cost } \\
\text { (baht/hour) }\end{array}$ & $\begin{array}{c}\text { Utilities cost } \\
\text { (baht/ hour) }\end{array}$ & $\begin{array}{c}\text { Maintenance costs } \\
\text { (baht/hour) }\end{array}$ \\
\hline Type 1 & 31,500 & 16,397 & 53 & 210 \\
Type 2 & 31,500 & 30,781 & 90 & 329 \\
Type 3 & 31,500 & 83,548 & 128 & 107 \\
\hline
\end{tabular}

\subsection{Mathematical Formulation}

The mathematical models presented were developed for the location and routing problem (LRP) by selecting the location of the infectious waste incinerator sites and arranging the transportation routes for the infectious waste collection of hospitals in Northeastern Thailand with the objectives and conditions determined according to the complicated actual problems relating to the frequency of infectious waste disposal for each hospital. The proposed mathematical model aims to achieve the lowest total costs. Parameters and decision variables used for the formulation of the model are defined and presented below with a brief explanation of each constraint.

Index

$$
\begin{aligned}
i, j & : \text { Hospital } \quad i, j=1,2, \ldots, n(n=325) \\
p & : \text { Potential Location } p=1,2, \ldots, \mathrm{m}(\mathrm{m}=21) \\
v & : \text { Vehicle } v=1,2, \ldots, V \\
k & : \text { Incinerators type }
\end{aligned}
$$

1 refers to the type of incinerator with a burning capacity of 100 kilograms/hour.

2 refers to the type of incinerator with a burning capacity of 300 kilograms/hour.

3 refers to the type of incinerator with a burning capacity of 600 kilograms/hour.

Set

$P$ : Set of potential Locations

$I$ : Set of hospitals

$V: \quad$ Set of vehicles

$K: \quad$ Set of incinerators

Parameters

$d_{i j}$ : Travelling distance from node $i$ to node $j$ (kilometer)

$c_{k}$ : Fixed cost of the incinerator $k$ (baht/month)

$\lambda_{i}$ : Average amount of infectious waste of hospital $i$ (kilogram/month)

$b_{k}$ : Burning capacity of incinerator $k$ (kilogram/hour)

$o_{k}$ : Variable cost of the incinerator $k$ (baht/hour)

$z$ : Total cost (baht/month)

$a$ : Fuel consumption cost of the vehicle (baht/kilometer)

$q_{S}:$ Vehicle capacity (kilogram)

$S$ : Average medical expenses per person (bath/person/month)

$f_{v}$ : Fixed cost of the vehicle (baht/trip/month) 
$\beta_{i}$ : Frequency of travelling to receive infectious waste from hospital $i$ (times / month)

$t$ : A number of hours in a month (hours) (720 hours/month)

$A$ : The maximum traveled distance for each vehicle (750 kilometers/trip)

Decision Variables

$h_{k p}=$ Number of hours per month that incinerator $k$ is operated at potential location $p$

$L_{i p v}=\left\{\begin{array}{cc}1 & \text { if vehicle } v \text { travels to hospital } i \text { and the potential location } p:(i, p \text { on the same vehicle route) } \\ 0 & \text { otherwise }\end{array}\right.$

$R_{i p}=\left\{\begin{array}{cc}1 & \text { if hospital } i \text { receives infectious waste disposal services at the potential locations } p \\ 0 & \text { otherwise }\end{array}\right.$

$N_{k p}=\left\{\begin{array}{cc}1 & \text { if incinerator } k \text { is selected at the potential location } p \\ 0 & \text { otherwise }\end{array}\right.$

$X_{i j}=\left\{\begin{array}{cc}1 & 1 \text { if hospital } i \text { is assigned to eliminate infectious waste at location } j \\ 0 & \text { otherwise }\end{array}\right.$

$Y_{p}=\left\{\begin{array}{cc}1 & \text { if potential locations } p \text { is selected as the infectious waste disposal facility } \\ 0 & \text { otherwise }\end{array}\right.$

Auxiliary Variable

$U_{i v} \quad$ Decision making variable to eliminate subtours.

Objective Function

$$
\min Z=\sum_{k \in K} \sum_{p \in P} c_{k} N_{k p}+\sum_{i \in I} \sum_{p \in P} \sum_{v \in V} f_{v} X_{i p v}+\sum_{p \in P} \sum_{k \in K} h_{k p} \boldsymbol{O}_{k} N_{k p}+\sum_{v \in V} \sum_{i \in I \cup P} \sum_{j \in I \cup P} a d_{i j} X_{i j v}+\sum_{p \in P} s l_{p} Y_{p}
$$

subject to

$\sum_{p \in P} Y_{p} \geq 1$

$\sum_{k \in K} N_{k p}=Y_{p}$

$\forall p$

$\sum_{j \in I \cup P} X_{i j v}=\sum_{j \in I \cup P} X_{j i v}$

$\forall i, \forall v$

$R_{i p} \leq Y_{p}$

$\forall i, \forall p, i \in I$

$\sum_{p \in P} R_{i p}=1$

$\forall i$

$R_{i p} L_{i p v}=\sum_{j \in I} x_{j p v} \sum_{j \in I \cup P} x_{i j v}$

$\forall i, \forall p, \forall v, i \in I, p \in P, v \in V$

$L_{i p v}=\sum_{j \in I} x_{j p v} \sum_{j \in I \cup P} x_{i j v}$

$\forall i, \forall p, \forall v, i \in I, p \in P, v \in V$

$X_{i i v}=0$

$\forall i, \forall v, i \in I, v \in V$

$\sum_{k \in K} b_{k}\left(h_{k p}-6\right) N_{k p} \geq \sum_{i \in I} \lambda_{i} R_{i p}$

$\forall p$

$0 \leq h_{k p} \leq t N_{k p}$

$\forall k, \forall p, k \in K$

$\sum_{i \in I} R_{i p} \geq Y_{p}$

$\forall p$

$\sum_{i \in I} \sum_{v \in V} X_{i p v} \geq Y_{p}$

$\forall p$ 


$$
\begin{aligned}
& \sum_{i \in I} \sum_{v \in V} X_{p i v} \geq Y_{p} \\
& X_{p i v} \leq Y_{p} \\
& X_{i p v} \leq Y_{p} \\
& \sum_{i \in I \cup P} \sum_{p \in P} X_{i p v} \leq 1 \\
& \sum_{p \in P} \sum_{i \in I \cup P} X_{p i v} \leq 1 \\
& \sum_{j \in I \cup P} \sum_{v \in V} X_{i j v}=\beta_{i} \\
& \sum_{j \in I \cup P} \sum_{v \in V} X_{j i v}=\beta_{i} \\
& \sum_{i \in I \cup P} \sum_{j \in I}\left[\left(\frac{\lambda_{j}}{\beta_{j}}\right) X_{i j v}\right] \leq q_{v} \\
& \sum_{i \in I \cup P} \sum_{j \in I \cup P} d_{i j} X_{i j v} \leq A \\
& U_{i v}-U_{j v}+n x_{i j v} \leq n-1 \\
& U_{i v} \geq 0 \\
& X_{i j v} \in\{0,1\} \\
& Y_{p} \in\{0,1\} \\
& R_{i p} \in\{0,1\} \\
& N_{b} \in\{0,1
\end{aligned}
$$$$
\forall p
$$$$
\forall i, \forall p, \forall v, i \in I, p \in P, v \in V
$$$$
\forall i, \forall p, \forall v, i \in I, p \in P, v \in V
$$$$
\forall v, v \in V
$$$$
\forall v, v \in V
$$$$
\forall i, i \in I, i \neq j
$$$$
\forall i, i \in I, i \neq j
$$$$
\forall v, v \in V, i \neq j
$$$$
\forall v, v \in V
$$$$
\forall i, \forall j, \forall v, i \in I, j \in I, v \in V
$$$$
\forall i, \forall v, i \in I, v \in V
$$

The objective of function (1) is to minimize the total cost, which consists of the fixed and variable costs of operating the incinerators, the fixed and variable costs of transportation and penalty costs. Constraint (2) guarantees that at least one location is selected as the infectious waste disposal facility. Constraint (3) determines that only one type of incinerator will be selected at the potential location. Constraint (4) ensures that if the vehicle has entered any node, it must also exit that node. Constraint (5) determines that all hospitals are able to obtain service of infectious waste disposal only from the operating location. Constraint (6) determines that each hospital must receive the infectious waste disposal service from only one operating location. Constraint (7) and (8) guarantee that when each infectious waste collection vehicle is collecting infectious waste from any hospital, the infectious waste must be delivered to only one operating location. Constraint (9) guarantees that once the infectious waste collection vehicle collects the infectious waste from any hospital, it never returns to the same hospital. Constraint (10) determines that the number of hours of operating the incineration at the potential location must be able to incinerate all of the infectious waste received. Constraint (1 1$)$ determines that the incinerator site must be operated continuously for not over 720 hours per month. Constraint (12) guarantees that the potential location must provide service to at least one hospital. Constraint (13) and (14) determine that if one infectious waste incinerator site is operated at any location, there must be at least one transportation route for entering and exiting the location. Constraint (15) and (16) guarantee that if the location is not an infectious waste disposal facility, no vehicle will travel to and from that location. Constraint (17) and (18) require that each vehicle can serve only one location and it must visit only one operating location along its route. Constraint (19) and (20) require that the infectious waste of each hospital will be collected according to the frequency specified by that hospital. Constraint (21) requires that the total quantity collection of infectious waste in each trip must not exceed the vehicle capacity. Constraint (22) determines that the total traveled distance of each vehicle in each trip must not exceed $\mathbf{7 5 0}$ kilometers. Constraint (23) eliminates any sub-tours. Constraint (24) determines that the value of auxiliary variables cannot be negative. Constraint (25), (26), (27) and (28) define the binary decision variable.

\section{Heuristic Development}

\subsection{Design and Development of the Heuristic}

This section presents the heuristic method that has been designed and developed to address the problems of the selection of incinerator locations and vehicle routing for the collection of infectious waste from hospitals in Northeast of Thailand, which are considered as NP-hard problems due to their complexity and large number of variables. The developed heuristic is called the Greedy Randomized Adaptive Large Neighborhood Search Procedure (GRALNSP) and applies the principles of the Greedy Randomized Adaptive Search Procedure (GRASP) and Adaptive Large Neighborhood Search (ALNS) for the local search to obtain the best solution with the least processing time. The GRALNSP is divided into two main processes. In the 
first process, the principle of the GRASP is applied. GRASP is an iterative process that is divided into two phases; the construction phase and improvement phase. To determine how many infectious waste disposal facilities should be operated in order to minimize the total system cost, the increase of the fixed operation cost of the incinerator will be compared to the decrease of the fixed and variable transportation costs when one more location is opened as a new facility. If the reduced transportation cost is greater than the incremental fixed operation cost of the incinerator, then it is still reasonable to consider opening one more facility for infectious waste disposal. The proposed heuristic begins with the case in which one infectious waste disposal facility is required. After GRASP and ALNS identify the best location for this case, then the cases in which two facilities, three facilities, four facilities and so on are required are evaluated. The process continues until the reduced transportation cost is less than the incremental fixed operation cost of the incinerator. The best number of the infectious waste disposal facilities is the one that incurs the least total system cost. The procedure of GRALNSP is described below and shown in Fig 2.

Section 1: Initial Solution and Improvement (GRASP)

\section{Phase 1: Initial Solution}

This phase is used to find locations and the number of locations that can operate the infectious waste incineration services. $N$ is the set of hospitals $(N=325)$ and $n$ is the number of potential locations that can operate.

1.1 Establish one location where infectious waste incineration can be operated.

There are 21 potential locations of incinerator operation, considering that only one potential location can operate infectious waste incineration services, or $n=1$. We start from position 1 , then switch to another position until all 21 potential locations are considered.

Step 1: Determine parameters and calculate the distance from the potential location to all hospitals or $\left\lceil\frac{N}{n}\right\rceil$ hospitals.

Step 2: Determine the potential locations that are able to operate an infectious waste incinerator with the ascending total distance.

Step 3: Select the potential locations that can operate the incinerator with a lowest total travelling distance of $30 \%$, create the restricted candidate list 1 (RCL 1) and check the number of the infectious waste incinerators serving $\left(P^{\prime}=P\right)$

Step 4: Randomize one potential location from RCL 1 as the first potential location of the operating incinerator (P1).

Step 5: Arrange the hospitals to receive the infectious waste disposal at the potential locations of the operating incinerator.

Step 6: Implementing the Saving Algorithm principle to arrange the transportation route of the infectious waste collection travelling from the hospital to the operating incinerator with the following conditions: infectious waste collection vehicles must have a capacity not exceeding 10,000 kilograms per vehicle with a waste collection distance not exceeding 750 kilometers per vehicle per trip. In addition, the infectious waste collection is processed at the frequency set by each hospital in one month, and then the type of the incinerator at an operating incineration service is determined.

\section{Phase 2: Improvement}

Step 7: Improve the results by implementing the Adaptive Large Neighborhood Search (ALNS).The structure of ALNS is shown in Fig.3.

The degree of destruction (d) is used to determine the number of hospitals removed from the solution. The proportions of $20 \%, 30 \%, 40 \%$ and $50 \%$ are used to find the optimal proportion for the highest degree of destruction. The result shows that the total cost of the proportion of $40 \%$ and $50 \%$ is higher than $20 \%$ and $30 \%$, giving a similar result. Thus, the highest proportion of the degree of destruction was chosen at $30 \%$. There are three destroy operators - Random Removal, Worst Removal and Relate Removal — which are used for destruction, and three repair operators - Greedy Insertion, Arbitrary Insertion, and Random Insertion-are used to repair the solution. Due to the case study being a large problem that has many variables, segmenting the destroy operators can increase the chance of finding the best solution. In this research, we divide the destroy operators into a small and large group, determining the degree of destruction in a small group as $1 \%-5 \%$ of all hospitals and $6 \%-30 \%$ for a large group. Table 2 shows the total cost comparison between the case of the segmentation of the group of destroy operators and not segmenting the group. In total, 25 case studies are used in the experiment and the input data - the number of hospitals - are different in each case. The result shows that in small-sized problems (cases 1-15), the results are not different because not many hospitals are in the solution, the impact of destruction is clearly visible and it is easy to find the best solution when repairing the solution. Therefore, groups with or without divided destroying operators in small-sized problems are no different. However, in the large-sized problems (cases 1625) a large number of hospitals are considered, and the results show that the separation of destroy operators increases the chance of finding the best solution. Randomizing the destroy operators in both small and large groups makes it possible to find the best solution in a different area. From the result, in the large-sized problems, the separation of destroy operators gives 
the best solution (the lowest total cost). Therefore, in this research, we choose to separate the destroy operators to solve the problem of the selection of the location of incinerators and vehicle routing for the infectious waste collection of hospitals in Northeast of Thailand.

7.1: Adjust the weight of the destroy and repair operators. At the beginning, define the weight of all the destroy and repair operators as equal to 1 .

7.2: Calculate the probability of each destroy and repair operator.

7.3: Randomize the number of hospitals based on their degree of destruction and repair.

7.4: Randomize a number between 0 and 1 for destroy operators.

7.5: Destroy the solution.

7.6: Randomize a number between 0 and 1 for the repair operators.

7.7: Repair the solution.

7.8: Determine acceptance and stopping criteria by implementing the Simulated Annealing (SA) principle.

7.9: Update the solution.

7.10 : Update the weight of the destroy and repair operators and check the number of iterations $(n=1,000)$

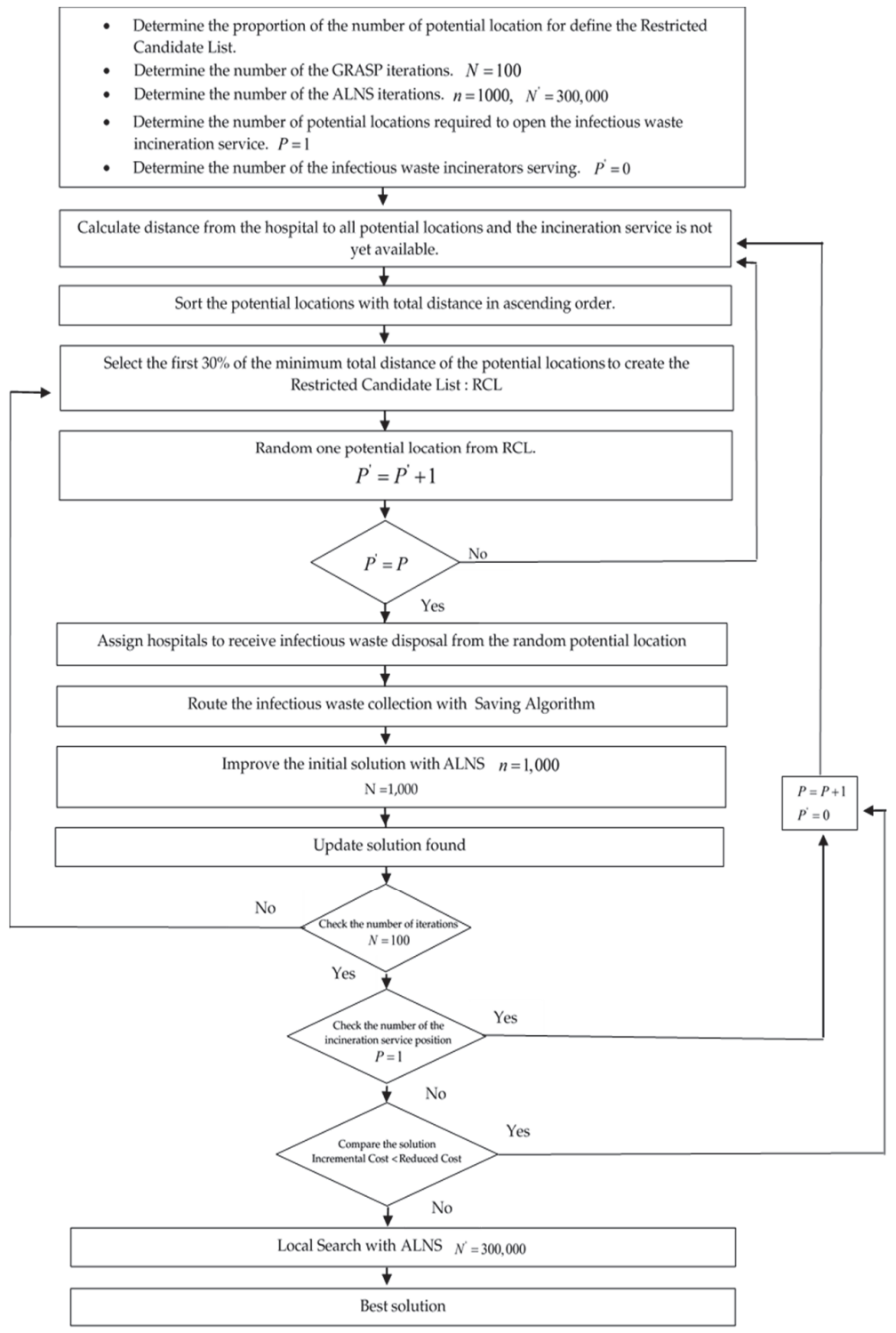

Fig. 2. The structure of the Greedy Randomized Adaptive Large Neighborhood Search Procedure (GRALNSP). 


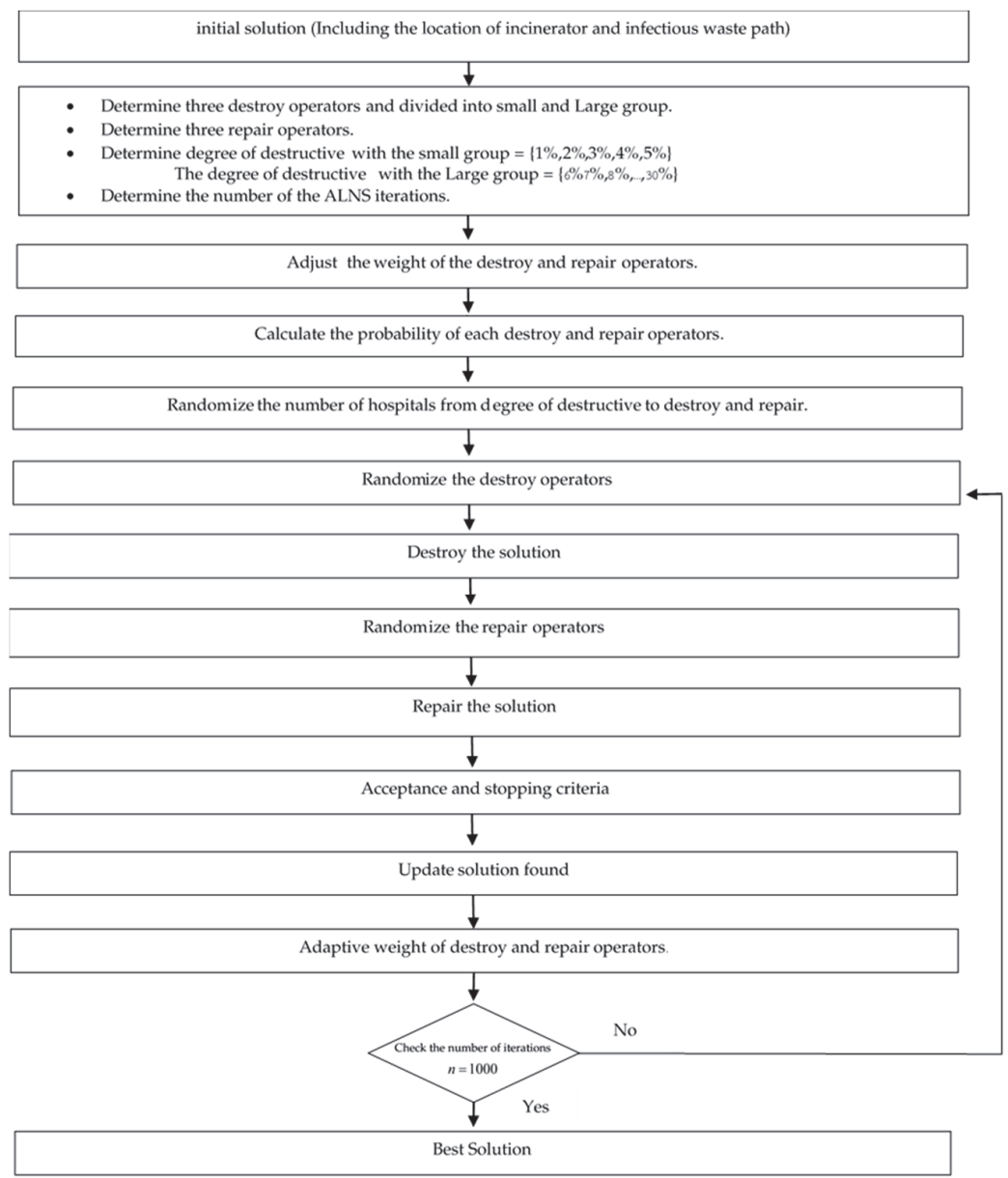

Fig. 3. The steps of the ALNS

Table 2

Result of comparisons total cost of dividing and not dividing the group of destroy operators

\begin{tabular}{|c|c|c|c|c|}
\hline \multirow{2}{*}{ Case } & \multirow{2}{*}{$\begin{array}{l}\text { The } \\
\text { number of } \\
\text { hospitals }\end{array}$} & \multicolumn{3}{|c|}{ Total Cost } \\
\hline & & Type 1 & Type 2 & Difference \\
\hline 1 & 5 & $2,828,234.92$ & $2,828,234.92$ & - \\
\hline 2 & 5 & $2,828,234.92$ & $2,828,234.92$ & - \\
\hline 3 & 5 & $2,840,466.67$ & $2,840,466.67$ & - \\
\hline 4 & 5 & $2,876,718.00$ & $2,876,718.00$ & - \\
\hline 5 & 8 & $1,661,712.00$ & $1,661,712.00$ & - \\
\hline 6 & 6 & $2,239,838.00$ & $2,239,838.00$ & - \\
\hline 7 & 10 & $2,841,654.00$ & $2,841,654.00$ & - \\
\hline 8 & 10 & $2,876,717.00$ & $2,876,717.00$ & - \\
\hline 9 & 10 & $2,841,654.00$ & $2,841,654.00$ & - \\
\hline 10 & 10 & $2,859,890.00$ & $2,859,890.00$ & - \\
\hline 11 & 10 & $2,896,360.00$ & $2,896,360.00$ & - \\
\hline 12 & 20 & $2,885,064.00$ & $2,885,064.00$ & - \\
\hline 13 & 20 & $2,874,408.00$ & $2,874,408.00$ & - \\
\hline 14 & 20 & $2,874,408.00$ & $2,874,408.00$ & - \\
\hline 15 & 20 & $3,134,984.73$ & $3,134,984.73$ & - \\
\hline 16 & 100 & $6,352,580.44$ & $6,371,103.84$ & $(18,523.40)$ \\
\hline 17 & 120 & $6,352,580.44$ & $6,393,384.49$ & $(40,804.05)$ \\
\hline 18 & 140 & $6,352,580.44$ & $6,393,810.63$ & $(41,230.19)$ \\
\hline 19 & 160 & $6,352,580.44$ & $6,393,384.49$ & $(40,804.05)$ \\
\hline 20 & 180 & $6,352,580.44$ & $6,393,384.49$ & $(40,804.05)$ \\
\hline 21 & 200 & $6,352,580.44$ & $6,371,103.84$ & $(18,523.40)$ \\
\hline 22 & 220 & $6,352,580.44$ & $6,393,384.49$ & $(40,804.05)$ \\
\hline 23 & 260 & $6,352,580.44$ & $6,393,384.49$ & $(40,804.05)$ \\
\hline 24 & 280 & $6,347,288.83$ & $6,371,103.84$ & $(23,815.01)$ \\
\hline 25 & 300 & $6,352,338.76$ & $6,371,103.84$ & $(18,765.08)$ \\
\hline
\end{tabular}

Remark ** Type 1 is total cost of dividing the group of destroy operators

Type 2 is total cost of not dividing the group of destroy operators The difference is Type1 - Type 2 
Step 8: Calculate the total cost.

Step 9: Perform 100 iterations of step 3.

1.2 Determine two locations to operate the infection waste incineration $\operatorname{service}(n=2)$.

Phase 1: Initial Solution

Step 1: There are 325 hospitals receiving infectious waste incineration services in the Northeast of Thailand. Calculate the total distance of 163 hospitals or $\left\lceil\frac{N}{n}\right\rceil$ hospitals travelling to all 21 operating potential locations.

Step 2: Determine the potential locations that are able to operate an infectious waste incinerator with the ascending total distance.

Step 3: Select a location with the first $30 \%$ of the lowest total distance where the incinerator can be operated to create the RCL1.

Step 4: Randomize one potential location from RCL1 as the first incinerator to operate at the location (P1) this round.

Step 5: Eliminate P1 and 163 hospitals that accounted for the total distance in Step 1. There are 163 hospitals remaining or $N-\left\lceil\frac{N}{n}\right\rceil$ and 20 locations where infectious waste incinerators can be operated. Take the obtained amount to calculate the new total distance. For each location where the incinerator can be operated, calculate the total distance from the remaining 162 hospitals, and list the total distance of the locations where the incinerator can be operated in ascending order.

Step 6: Select the potential location that can operate the incinerator with the first lowest total travelling distance 30\% and create the RCL 2, then randomize one location from RCL2 as the second incinerator to operate at the location (P2) this round. Step 7: Once P1 and P2 potential locations are determined for providing incineration services, then assign the hospitals receiving the service by taking into account the distance between the hospital and the nearest potential location for operating an incinerator. For instance, H01 hospital is located 35 and 50 kilometers from locations P1 and P2, respectively; therefore, $\mathrm{H} 01$ hospital is assigned to receive the infectious waste incineration service from location P1, etc.

Step 8: Arrange transportation routes to carry out infectious waste collection from hospitals using the Saving Algorithm method and determine the type of incinerator to operate the incineration service.

Phase 2: Improvement

Step 9: Improve the solution by using the Adaptive Large Neighborhood Search.

Step 10: Calculate the total cost.

Step 11: Compare the total cost of establishing one location for an incinerator site to the total cost of establishing two incinerator sites by considering the difference between the different costs of operating the infectious waste incinerator and the different costs of infectious waste collection vehicles. If the increased difference in the cost of operating the incinerator is less than the lower difference in the vehicle cost, then consider establishing the third incinerator site. On the contrary, if the difference in the cost of operating the infectious waste incinerator is greater than the lower difference of the vehicle cost, stop considering the establishment of an infectious waste incinerator site. However, if considering the location of a third infectious waste incinerator, the same process of the consideration of operating the infectious waste incinerators is followed. However, if the location of additional incinerators is not considered, the search for the location and the number of locations to operate the incinerator is halted and the solution found in section 2 is updated.

Section 2: The second improvement

In this section, the best solution from the GRALNSP is improved by implementing ALNS, consisting of the destroy and repair operators, as with the original processes.

\section{Result}

\subsection{Solving problems with mathematical models}

The solving of the problem is conducted by mathematical modeling and processing through A Mathematical Programming Language (AMPL) with Baron Solver version 19.3.22 running on an Intel® Core ${ }^{\mathrm{TM}}$ i5-8300H-CPU@2.30GHz with 16 GB RAM. The problems of the location selection of incinerators and the vehicle routing of the infectious waste collection of hospitals in the Northeast of Thailand is a large and complicated problem, especially the case of infectious waste collection routes due to the different frequency of waste collection per month according to the policy of each hospital. In addition, AMPL has limitations in processing the results, so it cannot solve large and complicated problems. Therefore, the experiment is divided into 15 sample cases, each of which has different input data, including the number of potential locations to establish 
the infectious waste incinerators, whether one, two or three locations. There are three types of infectious waste incinerators. The number of hospitals receiving the infectious waste incineration services is divided into three groups: a small group of five to nine hospitals, a medium group of 10 hospitals and a large group of 20 hospitals. The frequency of infectious waste collection is part of the complexity of the selection of locations and the arranging of the transportation route for the hospitals' infectious waste collection. In the actual situation, infectious waste collection is processed on average four times a month for community hospitals and eight times a month for provincial hospitals. Therefore, in the sample case, various forms of infectious waste collection frequency are tested, such as the frequency of one and two times per month, the frequency of two and four times per month and the frequency of four and eight times per month. The results obtained from AMPL processing are compared with the results obtained from GRALNSP using the same case study. GRALNSP is designed and developed using the $\mathrm{C}++$ language and processed through the Visual Studio 2019 program. A comparison of the result values of the GRALNSP and the AMPL program is represented in Table 3, showing the results from GRALNSP in a sample case of five hospitals with a frequency of infectious waste collection of one and two times per month (Case 1, Case 2). Both AMPL and GRALNSP can provide results with no difference.

Table 3

The result comparison of A Mathematical Programming Language (AMPL) and the GRALNSP.

\begin{tabular}{|c|c|c|c|c|c|c|c|c|c|c|}
\hline \multirow[b]{2}{*}{ Case } & \multicolumn{4}{|c|}{ Input Data } & \multicolumn{3}{|c|}{ Result from AMPL } & \multicolumn{2}{|c|}{ Result from GRALNSP } & \multirow{2}{*}{$\begin{array}{c}\text { Difference } \\
\text { of } \\
\text { total cost } \\
(\%)\end{array}$} \\
\hline & $\begin{array}{c}\text { Number } \\
\text { of } \\
\text { potential } \\
\text { locations }\end{array}$ & $\begin{array}{l}\text { Types of } \\
\text { incinerator }\end{array}$ & $\begin{array}{c}\text { Number } \\
\text { of } \\
\text { hospitals }\end{array}$ & $\begin{array}{c}\text { Frequency } \\
\text { (times/mon } \\
\text { th) }\end{array}$ & Status & $\begin{array}{c}\text { Total cost } \\
\text { (baht/month) }\end{array}$ & $\begin{array}{l}\text { Processing } \\
\text { Time(s) }\end{array}$ & $\begin{array}{c}\text { Total cost } \\
\text { (baht/month) }\end{array}$ & $\begin{array}{c}\text { Processing } \\
\text { Time(s) }\end{array}$ & \\
\hline Case 1 & 1 & 2 & 5 & 1,2 & Global optimal & $2,828,235$ & 9.70 & $2,828,235$ & 3.65 & - \\
\hline Case 2 & 2 & 2 & 5 & 1,2 & Global optimal & $2,828,235$ & 12.90 & $2,828,235$ & 8.17 & - \\
\hline Case 3 & 2 & $1,2,3$ & 5 & 2,4 & Upper bound & $2,840,478$ & $8,397.73$ & $2,840,467$ & 7.85 & 0.0004 \\
\hline Case 4 & 2 & $1,2,3$ & 5 & 4,8 & Upper bound & $2,876,775$ & $27,002.09$ & $2,876,718$ & 7.01 & 0.0020 \\
\hline Case 5 & 2 & $1,2,3$ & 8 & 4,8 & Upper bound & $1,662,983$ & $72,865.64$ & $1,661,712$ & 8.11 & 0.0764 \\
\hline Case 6 & 3 & $1,2,3$ & 6 & 4,8 & Upper bound & $2,398,646$ & $51,634.44$ & $2,239,838$ & 14.87 & 6.6207 \\
\hline Case 7 & 2 & 2 & 10 & 1,2 & Upper bound & $2,841,654$ & $65,603.86$ & $2,841,654$ & 6.64 & 0.0000 \\
\hline Case 8 & 2 & 1,2 & 10 & 1,2 & Upper bound & $2,952,729$ & $7,072.52$ & $2,876,717$ & 8.5 & 2.5743 \\
\hline Case 9 & 2 & $1,2,3$ & 10 & 1,2 & Upper bound & $2,841,654$ & $5,134.09$ & $2,841,654$ & 9.77 & 0.0000 \\
\hline Case 11 & 2 & $1,2,3$ & 10 & 4,8 & Upper bound & $2,900,769$ & $58,346.41$ & $2,896,360$ & 9.8 & 0.1520 \\
\hline Case 12 & 2 & $1,2,3$ & 20 & 2,4 & Upper bound & $2,887,482$ & $50,660.16$ & $2,885,064$ & 8.68 & 0.0837 \\
\hline Case 13 & 2 & $1,2,3$ & 20 & 1,2 & Upper bound & $2,875,008$ & $45,699.64$ & $2,874,408$ & 3.58 & 0.0209 \\
\hline Case 14 & 2 & $1,2,3$ & 20 & 4,8 & Upper bound & $2,988,263$ & $49,696.95$ & $2,874,408$ & 3.58 & 3.8101 \\
\hline Case 15 & 2 & $1,2,3$ & 20 & 2,4 & Upper bound & $3,142,889$ & $56,318.23$ & $3,134,985$ & 6.24 & 0.2515 \\
\hline
\end{tabular}

The AMPL program provides the results of the global optimal solution, but GRALNSP uses less computational time. When comparing the results to the sample case with small groups of hospitals receiving the service, those hospitals have a higher frequency of infectious waste collection of two or four and four or5 eight times per month (Case 3-Case 6). The AMPL provides the solution: the upper bound takes a processing time of more than 20 hours to complete. There are significant differences in the results of the total cost and processing time. The results are same as the comparison of results among the medium and large hospitals (Case 7-Case 14), showing that AMPL also cannot provide the results for the global optimal solution. In addition, the results of both methods cause different total costs; in particular, GRALNSP provides better results with less computation time. Regarding the results of the comparison, the obtained results are the total costs of both GRALNSP and the AMPL program and indicate that, when the problems become larger and more complicated, the AMPL program is unable to provide the results for the global optimal solution and it takes a long time to process, or in some cases it cannot find the possible results due to program limitations. On the contrary, the results obtained by GRALNSP show that it is an efficient method to solve large and complicated problems with fast processing time. Afterward, the data for all 15 sample cases were tested for their average difference using a statistical method. The researchers used a paired t-test with a significance level of 0.05 , and the results are shown in Table 4 .

Table 4

Results of paired t-test

\begin{tabular}{cc}
\hline Detail & $p-$ Value \\
\hline Total Cost & 0.08 \\
Processing Time & 0.00
\end{tabular}

From Table 4, the results of the analysis of total cost differences obtained from AMPL and GRALNSP with the paired t-test showed a $p$-Value higher than the 0.05 level of significance; therefore, the average of the difference between the total costs shows no significant difference between the two methods. On the other hand, the $p$-Value of processing time is 
lower than a 0.05 level of significance, demonstrating differences between the AMPL and GRALNSP. Therefore, the GRALNSP reduces the processing time for problem solving while producing a total cost that is not different from the result provided by AMPL. The GRALNSP is a suitable and highly effective method for solving complex problems such as the location selection of incinerators and the vehicle routing of infectious waste collection of hospitals in the Northeast of Thailand, which is the case study problem.

\subsection{Case study}

The GRALNSP was used to solve the case study of the location selection of incinerators and vehicle routing for infectious waste collection for hospitals in the Northeast of Thailand, as well as the lowest total cost. There are 21 potential locations and 325 hospitals in the Northeast of Thailand. The results are detailed in Tables 5-6, and suitable locations for incinerators and vehicle routing for infectious waste collection for hospitals in the Northeast of Thailand are shown in Fig. 4. Tables 5-6 show the results of the solution to the location selection and vehicle routing of infectious waste transportation for hospitals in the Northeast of Thailand.

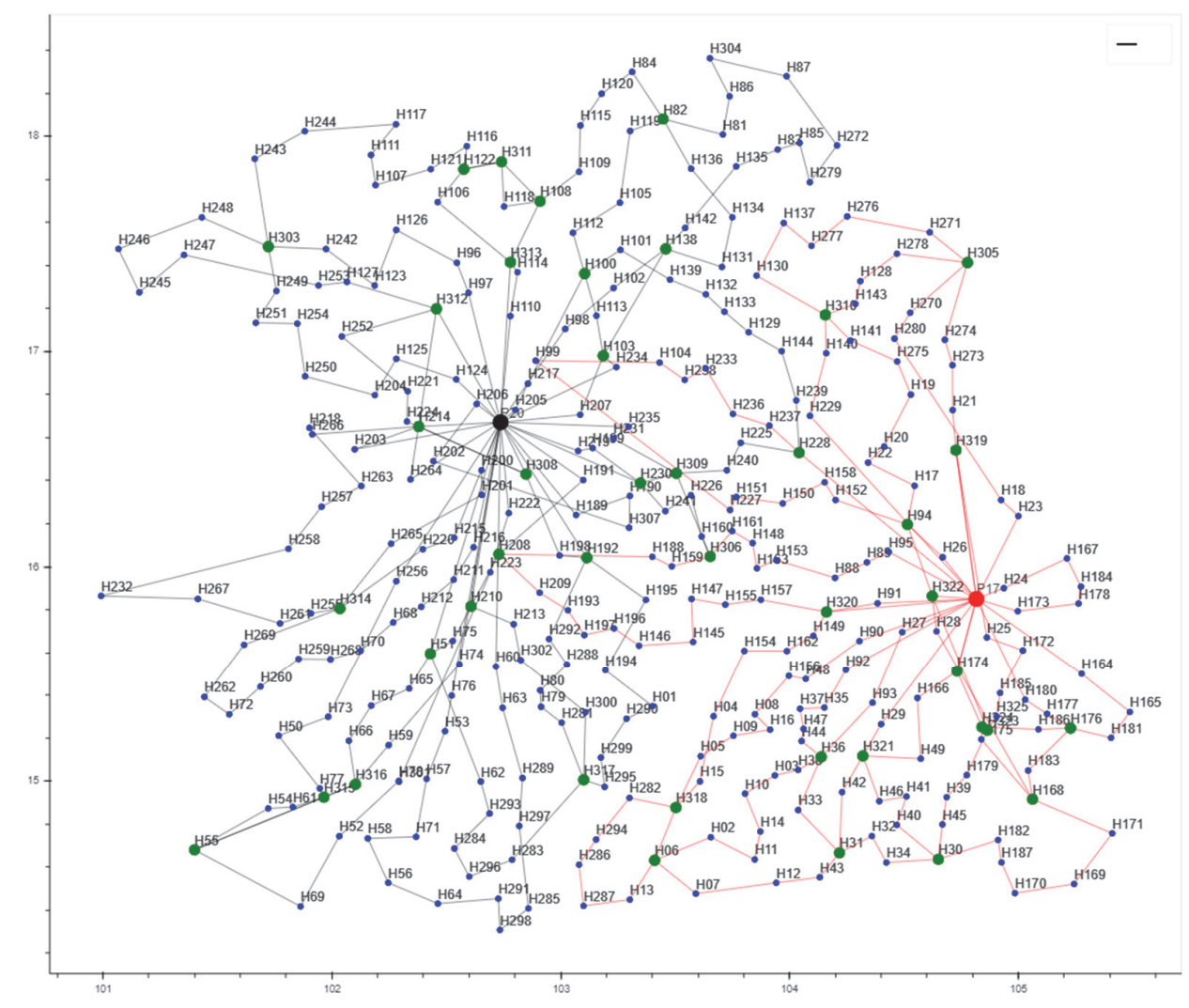

Fig. 4. Suitable location of incinerators and vehicle routing for the infectious waste collection of hospitals in the Northeast of Thailand

There are two suitable locations to operate the incinerators, namely P17 and P20. The P17 location is located in the area of Pathum Rajawongsa District, Amnat Charoen Province, consisting of 138 hospitals receiving the infectious waste incineration service. It uses an incinerator with a maximum burning capacity of 600 kilogram/hour to burn 303,148.84 kilograms of infectious waste per month, taking a total burning time of 513.89 hours per month. It contains 10 infectious waste collection routes, with the waste collection process being carried out four times a month for each route. and with a total collection distance of 24,055.24 kilometers per month, at a total cost of 2,774,149.68 baht per month. The P20 location is located in Nam Phong District, Khon Kaen Province, consisting of 187 hospitals receiving the infectious waste incineration service. It uses an incinerator with a maximum burning capacity of 600 kilograms/hour to burn 416,831.60 kg of infectious waste per month, taking a total burning time of 709.57 hours per month. It contains 15 infectious waste collection routes with a waste collection process carried out four times a month in each route and with a total collection distance of 38,401.48 kilometers per month, at a total cost of $3,494,820.72$ baht per month. From the results, the locations to operate infectious waste incinerators and optimal routes for the collection of infectious waste to hospitals in the Northeast of Thailand represent a lowest total cost of 6,268,970.41 baht per month. Fig. 4 presents the suitable locations of incinerators and vehicle routing for infectious waste collection for hospitals in the Northeast of Thailand. The black circular point is the P17 location for establishing the incinerator site. The hospitals receiving the service are represented by blue dots and the infectious waste 
collection routes are represented by black lines. The orange circular point is the P20 location for establishing the incinerator site. The infectious waste collection routes are represented by orange lines. The green point represents the hospital with a frequency of infectious waste collection of eight times per month, which represents two infectious waste collection routes.

Table 5

The result of case study with the GRALNSP

\begin{tabular}{|c|c|c|c|c|}
\hline 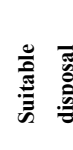 & Vehicle routing & $\begin{array}{c}\text { Infectious } \\
\text { waste } \\
\text { collection } \\
\text { (times/month) }\end{array}$ & 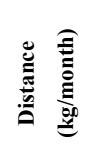 & $\begin{array}{l}\text { Infectious } \\
\text { waste } \\
\text { (kg/month) }\end{array}$ \\
\hline \multirow{10}{*}{ P17 } & Route 1 : P17,H228, H237, H236, H233, H238,H104, H99, H227, H151, H150, H158,H152 „H94, H26, P17 & 4 & $2,687.88$ & $16,567.52$ \\
\hline & $\begin{array}{l}\text { Route } 2 \text { : P17, H91,H320, H157, H155,H147,H145,H146,H196,H197, } \\
\mathrm{H} 193, \mathrm{H} 209, \mathrm{H} 208, \mathrm{H} 188, \mathrm{H} 159, \mathrm{H} 306, \mathrm{H} 161, \mathrm{H} 148, \mathrm{H} 163, \mathrm{H} 153, \mathrm{H} 88, \mathrm{H} 89, \mathrm{H} 95, \mathrm{P} 17\end{array}$ & 4 & $2,664.92$ & $36,381.52$ \\
\hline & $\begin{array}{l}\text { Route3:P17,H90,H48,H156,H8,H16,H9,H5,H318,H282,H294,H286,H287,H13,H6,H2,H1 1,H14,H10,H3,H3 } \\
\text { 8,H36,H93,H27,P17 }\end{array}$ & 4 & $2,993.44$ & $37,530.40$ \\
\hline & Route 4 : P17,H23,H18,H280,H270,H305,H278,H128,H143,H310,H140,H229,P17 & 4 & $2,422.72$ & $20,995.64$ \\
\hline & Route 5 : P17,H320,H149,H162,H154,H4,H15,H318,H6,H7,H12,H43,H31,H42,H321,H29,P17 & 4 & $2,396.12$ & $39,487.40$ \\
\hline & $\begin{array}{l}\text { Route6:P17,H322,H94,H17,H22,H20,H19,H275,H141,H310,H130,H137,H277,H276,H271,H305,H274,H27 } \\
\text { 3,H21,H319,P17 }\end{array}$ & 4 & $2,719.36$ & $34,613.84$ \\
\hline & $\begin{array}{l}\text { Route7:P17,H92,H35,H37,H47,H44,H36,H33,H31,H32,H34,H30,H45,H39,H179,H323,H325,H185,H172,H } \\
\text { 25,H319,P17 }\end{array}$ & 4 & $2,821.80$ & $39,034.52$ \\
\hline & $\begin{array}{l}\text { Route8:P17,H180,H177,H176,H186,H324,H175,H168,H171,H169,H170,H187,H182,H30,H40,H41,H46,H3 } \\
\text { 21,H49,H166,H174,P17 }\end{array}$ & 4 & $2,656.84$ & $37,174.00$ \\
\hline & Route 9 : P17,H164,H165,H181,H176,H183,H168,H28,H322,H323,H324,H174,P17 & 4 & $2,084.40$ & $38,108.00$ \\
\hline & Route10 : P17,H173,H178,H184,H167,H24,P17 & 4 & 607.76 & $3,256.00$ \\
\hline \multicolumn{2}{|r|}{ 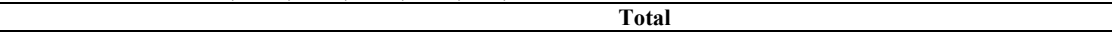 } & & $24,055.24$ & $303,148.84$ \\
\hline Burnin & 513.89 hour $/$ month & & & \\
\hline \multicolumn{5}{|c|}{ Type of Incinerator $600 \quad$ kilogram/hour } \\
\hline
\end{tabular}

Table 6

The result of case study with the GRALNSP(Cont.)

\begin{tabular}{|c|c|c|c|c|}
\hline 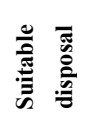 & Vehicle routing & $\begin{array}{c}\text { Infectious waste } \\
\text { collection } \\
\text { (times/month) }\end{array}$ & 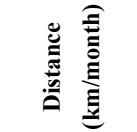 & $\begin{array}{l}\text { Infectious } \\
\text { waste } \\
\text { (kg/month) }\end{array}$ \\
\hline \multirow{16}{*}{$\mathrm{P} 20$} & Route 1: P20,H235,H231,H309,H306,H160,H226,H241,H230,H199,H219,P20 & 4 & $1,523.32$ & $27,213.04$ \\
\hline & Route 2: P20,H189,H190,H307,H202,H206,P20 & 4 & $1,307.76$ & $22,843.20$ \\
\hline & Route 3: P20,H60,H63,H289,H297,H285,H298,H291,H64,H56,H58,H71,H57,H53,H76,P20 & 4 & $2,936.04$ & $27,558.60$ \\
\hline & Route 4 : P20,H74,H59,H316,H315,H55,H69,H52,H78,H301,H223,H222,P20 & 4 & $2,924.40$ & $28,946.84$ \\
\hline & Route 5 : P20,H51,H65,H67,H66,H316,H55,H54,H61,H315,H77,H50,H73,H256,P20 & 4 & $2,968.60$ & $38,229.00$ \\
\hline & $\begin{array}{l}\text { Route6:P20,H234,H103,H138,H131,H134,H136,H82,H84,H120,H115,H109,H108,H118,H311, } \\
\text { H122,H106,H313,H114,H110,P20 }\end{array}$ & 4 & $2,905.84$ & $37,551.00$ \\
\hline & $\begin{array}{l}\text { Route7:P20,H210,H75,H51,H62,H293,H284,H296,H283,H317,H295,H299,H290,H1,H194,H19 } \\
\text { 5, H192,P20 }\end{array}$ & 4 & $2,979.68$ & $28,704.76$ \\
\hline & Route 8 : P20,H312,H127,H253,H247,H245,H246,H248,H303,H242,H123,H126,H96,H97,P20 & 4 & $2,687.56$ & $15,921.92$ \\
\hline & $\begin{array}{l}\text { Route 9: } \\
\text { P20,H216,H211,H212,H68,H70,H268,H259,H260,H72,H262,H269,H314,H220,H215,P20 }\end{array}$ & 4 & $2,317.44$ & $27,174.00$ \\
\hline & $\begin{array}{l}\text { Route } 10 \text { : } \\
\text { P20,H200,H201,H265,H314,H255,H261,H267,H232,H258,H257,H263,H218,H266,H214-P20 }\end{array}$ & 4 & $2,876.08$ & $33,960.00$ \\
\hline & $\begin{array}{l}\text { Route11:P20,H205,H217,H100,H112,H105,H119,H82,H81,H86,H304,H87,H272,H279,H85,H8 } \\
\text { 3,H135,H142,H138,H102,H98,P20 }\end{array}$ & 4 & $2,899.52$ & $20,925.00$ \\
\hline & $\begin{array}{l}\text { Route12:P20,H124,H125,H204,H250,H254,H251,H249,H303,H243,H244,H117,H111,H107,H1 } \\
\text { 21,H116,H122,H311,H108,H313,P20 }\end{array}$ & 4 & $2,951.24$ & $34,180.20$ \\
\hline & $\begin{array}{l}\text { Route13:P20,H191,H208,H210,H213,H302,H300,H317,H281,H79,H80,H288,H292,H192,H198 } \\
\text {,H308,P20 }\end{array}$ & 4 & $2,363.88$ & $33,346.36$ \\
\hline & $\begin{array}{l}\text { Route14:P20,H207,H103,H113,H100,H101,H139,H132,H133,H129,H144,H239,H228,H225,H2 } \\
\text { 40,H309,H230,P20 }\end{array}$ & 4 & $2,287.20$ & $19,717.04$ \\
\hline & Route 15 : P20,H203,H214,H308,H224,H221,H252,H312,H264,P20 & 4 & $2,472.92$ & $20,560.64$ \\
\hline & Total & & $38,401.48$ & $416,831.60$ \\
\hline \multicolumn{5}{|c|}{$\begin{array}{ll}\text { Burning time } & 709.57 \text { hour } / \text { month }\end{array}$} \\
\hline \multicolumn{5}{|c|}{ Type of Incinerator $600 \quad$ kilogram/hour } \\
\hline \multicolumn{5}{|c|}{ Total cost $\quad 3,494,820.72$ baht/month } \\
\hline
\end{tabular}

\section{Conclusion}

This research presents the GRALNSP approach for solving the LRP problem of location selection and arranging transportation routes for the infectious waste collection of hospitals in the Northeast of Thailand for the lowest total cost. The feature of the LRP problem is the consideration of the incinerator locations and the infectious waste collection routes at the same time by selecting an appropriate incinerator size and determining the potential health penalties if infectious waste disposal is established in that area. Regarding the location for the establishment of 
infectious waste disposal sites, it is necessary to consider a location situated in an industrial area according to the land use allocation in the announcement of the Ministerial Regulation on the enforcement of the city plan of each province in the Northeast of Thailand, consisting of 21 locations. In addition, each location can establish only one type of incinerator, and only one incinerator can be operated. There are 325 hospitals in the Northeast of Thailand receiving an infectious waste incineration service, and each of them can select to use a service from only one operating incinerator site. The researchers solved this problem by implementing mathematical modeling with the AMPL program. In total, 15 cases of problematic samples were used, with various complexities, including the number of locations where an infectious incinerator can be established, frequency of infectious waste collection or the type of determined infectious waste incinerator, etc. The findings show that the AMPL program can provide the results of a global optimal in the case of a small-sized problem with low complexity, although this requires more than 20 hours of processing time. In addition, it is also unable to solve large and complicated problems when compared to the results obtained from the GRALNSP. However, the results of both the AMPL program and the GRALNSP have different total costs and the processing time. The findings indicate that the GRALNSP is more efficient and also useful for solving the case studies. The results obtained from the developed heuristic method showed that there were two suitable locations for operating the infectious waste incinerators, in the areas of Pathum Rajawongsa District, Amnat Charoen Province and Nam Phong District, Khon Kaen Province with the lowest total cost of $6,268,970.41$ baht per month. However, if the volume of infectious waste is likely to increase every year, the management of the proper disposal of infectious waste may be changed, or the scope of the infectious waste disposal area may be expanded, changing the least total cost. This research can therefore be considered as a guideline for policy-level decisions regarding the infectious waste disposal operations of the relevant agencies. In future research, the GRALNSP may expand its scope of consideration for the mitigation of potential environmental risks when infectious waste is transported within community areas. In addition, it may be applied to consider the location of the establishment of an incinerator along with arranging the transportation routes of infectious waste collection at the national level to achieve the lowest total cost, or it may be applied to other similar problems.

\section{References}

Aboutahoun, A. (2012). Combined distance-reliability model for hazardous waste transportation and disposal. Life Sciences Journal, 9(2), 1286-1295.

Alçada-Almeida, L., Coutinho-Rodrigues, J., \& Current, J. (2009). A multiobjective modeling approach to locating incinerators. Socio-Economic Planning Sciences, 43(2), 111-120.

Alumur, S., \& Kara, B. Y. (2007). A new model for the hazardous waste location-routing problem. Computers \& Operations Research, 34(5), 1406-1423.

Boyer, O., Sai Hong, T., Pedram, A., Mohd Yusuff, R. B., \& Zulkifli, N. (2013). A mathematical model for the industrial hazardous waste location-routing problem. Journal of Applied Mathematics, 2013.

Chauhan, A., \& Singh, A. (2016). Healthcare waste management: a state-of-the-art literature review. International Journal of Environment and Waste Management, 18(2), 120-144.

Chen, S., Chen, R., Wang, G. G., Gao, J., \& Sangaiah, A. K. (2018). An adaptive large neighborhood search heuristic for dynamic vehicle routing problems. Computers \& Electrical Engineering, 67, 596-607.

Contardo, C., Cordeau, J. F., \& Gendron, B. (2014). A GRASP+ ILP-based metaheuristic for the capacitated location- routing problem. Journal of Heuristics, 20(1), 1-38.

Das, S., \& Bhattacharyya, B. K. (2015). Optimization of municipal solid waste collection and transportation routes. Waste Management, 43, 9-18.

Department of Pollution Control Thailand state of pollution Report 2018. Viewed 21 May 2019, http://www.pcd.go.th /public/Publications/print_report.cfm

Dotoli, M., \& Epicoco, N. (2017). A vehicle routing technique for hazardous waste collection. IFAC-PapersOnLine, 50(1), 9694-9699.

Energy Regulatory Commission . Regulation of the Energy Regulatory in 2017, viewed 3 May 2019, http://www.erc.or.th

Erkut, E., \& Neuman, S. (1989). Analytical models for locating undesirable facilities. European Journal of Operational Research, 40(3), 275-291.

Gao, S., Wang, Y., Cheng, J., Inazumi, Y., \& Tang, Z. (2016). Ant colony optimization with clustering for solving the dynamic location routing problem. Applied Mathematics and Computation, 285, 149-173.

Hamidi, M., Farahmand, K., Sajjadi, S., \& Nygard, K. (2014). A heuristic algorithm for a multi-product four-layer capacitated location-routing problem. International Journal of Industrial Engineering Computations, 5(1), 87-100.

Kazantzi, V., Kazantzis, N., \& Gerogiannis, V. C. (2011). Risk informed optimization of a hazardous material multi-periodic transportation model. Journal of Loss Prevention in the Process Industries, 24(6), 767-773. 
Koç, Ç. (2016). A unified-adaptive large neighborhood search metaheuristic for periodic location-routing problems. Transportation Research Part C: Emerging Technologies, 68, 265-284.

Li, Y., Chen, H., \& Prins, C. (2016). Adaptive large neighborhood search for the pickup and delivery problem with time windows, profits, and reserved requests. European Journal of Operational Research, 252(1), 27-38.

Liu, R., Tao, Y., \& Xie, X. (2019). An adaptive large neighborhood search heuristic for the vehicle routing problem with time windows and synchronized visits. Computers \& Operations Research, 101, 250-262.

Maneein J. Infectious waste management of local government of Thailand. Master of Science Program in Sustainable Environmental Management, National Institute of Development Administration, Bankok, Thailand. 2013.

Nagy, G., \& Salhi, S. (2007). Location-routing: Issues, models and methods. European Journal of Operational Research, 177(2), 649-672.

Norese, M. F. (2006). ELECTRE III as a support for participatory decision-making on the localisation of waste-treatment plants. Land Use Policy, 23(1), 76-85.

Praseeratasang, N., Pitakaso, R., Sethanan, K., Kosacka-Olejnik, M., \& Theeraviriya, C. (2019). Adaptive Large Neighborhood Search to Solve Multi-Level Scheduling and Assignment Problems in Broiler Farms. Journal of Open Innovation: Technology, Market, and Complexity, 5(3), 37.

Prodhon, C., \& Prins, C. (2014). A survey of recent research on location-routing problems. European Journal of Operational Research, 238(1), 1-17.

Rabbani, M., Heidari, R., Farrokhi-Asl, H., \& Rahimi, N. (2018). Using metaheuristic algorithms to solve a multi-objective industrial hazardous waste location-routing problem considering incompatible waste types. Journal of Cleaner Production, 170, 227-241.

Rakas, J., Teodorović, D., \& Kim, T. (2004). Multi-objective modeling for determining location of undesirable facilities. Transportation Research Part D: Transport and Environment, 9(2), 125-138.

Schneider, M., \& Drexl, M. (2017). A survey of the standard location-routing problem. Annals of Operations Research, 259(12), 389-414.

Seubsiri, K. (2011). Survey of Infectious Waste Incinerator Management in a Community Hospital in the Upper Northeast Area, Doctor of Philosophy Program in Industrial Engineering, Ubon Ratchathani University, Ubon Ratchathani, Thailand.

Sirirak, W., \& Pitakaso, R. (2018). Marketplace Location Decision Making and Tourism Route Planning. Administrative Sciences, 8(4), 72.

Sresanpila, P., \& Sindhuchao, S. (2018). Solving the Problem of the Selection of the Size and Multi Depot Location Case Study : Elimination of Infectious Waste of Community Hospitals in the Upper Part of Northeast Thailand. UBU Engineering Journal, 9(1), 39-47.

Tang, S. H., Boyer, O., Pedram, A., Yusuff, R. B. M., \& Zulkifli, N. (2013). A review on multiple criteria undesirablefacility location problems. Journal of Basic and Applied Scientific Research, 3(8), 708-713.

Tuzkaya, G., Önüt, S., Tuzkaya, U. R., \& Gülsün, B. (2008). An analytic network process approach for locating undesirable facilities: an example from Istanbul, Turkey. Journal of Environmental management, 88(4), 970-983.

Theeraviriya, C., Pitakaso, R., Sillapasa, K., \& Kaewman, S. (2019). Location decision making and transportation route planning considering fuel consumption. Journal of Open Innovation: Technology, Market, and Complexity, 5(2), 27.

Theeraviriya, C., Sirirak, W., \& Praseeratasang, N. (2020). Location and routing planning considering electric vehicles with restricted distance in agriculture. World Electric Vehicle Journal, 11(4), 61.

Wichapa, N., \& Khokhajaikiat, P. (2017). Using the hybrid fuzzy goal programming model and hybrid genetic algorithm to solve a multi-objective location routing problem for infectious waste disposal. Journal of Industrial Engineering and Management (JIEM), 10(5), 853-886.

Wichapa, N., \& Khokhajaikiat, P. (2018). Solving a multi-objective location routing problem for infectious waste disposal using hybrid goal programming and hybrid genetic algorithm. International Journal of Industrial Engineering Computations, 9(1), 75-98.

Yadav, V., \& Karmakar, S. (2020). Sustainable collection and transportation of municipal solid waste in urban centers. Sustainable Cities and Society, 53, 101937.

Zhao, L., Wang, X., \& Qian, Y. (2012). Analysis of factors that influence hazardous material transportation accidents based on Bayesian networks: A case study in China. Safety science, 50(4), 1049-1055.

Zhao, J., \& Verter, V. (2015). A bi-objective model for the used oil location-routing problem. Computers \& Operations Research, 62, 157-168.

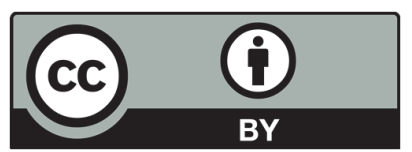

(C) 2021 by the authors; licensee Growing Science, Canada. This is an open access article distributed under the terms and conditions of the Creative Commons Attribution (CCBY) license (http://creativecommons.org/licenses/by/4.0/). 